\title{
Comparative Study of Bronchial Hyperresponsiveness Between Football and Judo Groups in Prepubertal Boys
}

\author{
Moez Triki ${ }^{1, *}$; Haithem Rebai ${ }^{1}$; Chirine Aouichaoui ${ }^{1}$; Mohammed Shamssain ${ }^{2}$; Kaouthar \\ Masmoudi ${ }^{3}$; Nicole Fellmann ${ }^{4,5}$; Hela Zouari ${ }^{1}$; Nouri Zouari ${ }^{3}$; Zouhair Tabka ${ }^{1}$ \\ ${ }^{1}$ Department of Physiology and Lung Function Testing, Faculty of Medicine, University of Sousse, Soussa, Tunisia \\ ${ }^{2}$ Division School of Health Sciences, Darwin Building, University of Sunderland, Sunderland, UK \\ ${ }^{3}$ Bourguiba Hospital of Sfax, University of Sfax, Sfax, Tunisia \\ ${ }_{5}^{4}$ Laboratory of Sports Physiology and Biology, Faculty of medicine, University of Auvergne, Clermont-Ferrand, France \\ ${ }^{5} \mathrm{G}$. Montpied Hospital, Clermont-Ferrand, France \\ *Corresponding author: Moez Triki, Department of Physiology and Lung Function Testing, Faculty of Medicine, University of Sousse, Soussa, Tunisia. Tel: +216-97360384, Fax +216-73226702, \\ E-mail: trikimoez27@yahoo.fr
}

Received: October 4, 2013; Accepted: December 9, 2014

\begin{abstract}
Background: Exercise induced bronchospasm (EIB) commonly occurs during exercise. The comparative effects of different sports on airway responsiveness among prepubertal boys remain to be determined.

Objectives: To assess differences in post exercise spirometry between footballers, judokas and a control group in prepubertal boys.

Patients and Methods: A total of ninety six prepubertal boys were studied. Bronchial hyper responsiveness (BHR) to exercise challenge test was defined by a diagnosis of baseline spirometry, followed by an incremental exercise test. To date, the best test to confirm EIB may simply be standard pulmonary function testing before and after high-intensity exercise. A 10\% or greater post-challenge fall in forced expiratory volume in FEV1 is used as a diagnostic criterion.

Results: There was no significant difference in baseline spirometry between all groups $(\mathrm{P}>0.05)$. The post exercise spirometry test revealed the presence of EIB in 16 of $32(50 \%)$ footballers against 9 out of $32(28.12 \%)$ in both judokas and control subjects at 5 min after the exercise. Also, there was a significantly higher decrease $(\mathrm{P}<0.05)$ in mean FEV1 at 5 minuts in footballers $(-9.60 \pm 6.18)$ compared to judokas $(-5.41 \pm 5.85)$

Conclusions: The footballers have more BHR than judokas, especially at $5 \mathrm{~min}$ after the exercise. This may be due to prolonged hyperventilation, atopy, and increased exposure to inhaled allergens and pollutants during training and competition.
\end{abstract}

Keywords: Bronchial Hyperresponsiveness; Exercise Induced Bronchospasm; Football; Judo; Spirometry; Prepubertal Boys

\section{Background}

It is widely accepted that regular physical activity is strongly associated with reduced rates of chronic diseases such as cancer, cardiovascular events and non-insulindependent diabetes mellitus. However, there is much less evidence for the potential beneficial effect of physical activity on lung health (1). In fact, some prospective studies in children (2) and in adult twins (3) have shown that the development of asthma was associated with decreased physical activity.

Furthermore, it has been shown that there is a strong and consistent negative relationship between physical activity and bronchial hyper responsiveness (BHR) in adults (1). The findings suggest that a relatively small amount of physical activity would markedly reduce BHR in the general population.

Although exercise in itself is considered bronchodilating (4), careful monitoring of maximal expiratory flow and airway resistance during exercise indicates that broncho- constriction may occur during prolonged and/or interval exercise (i.e. exercise involving variations in work intensity) (5). A high prevalence of respiratory symptoms in relation to exercise (6-8) and BHR to physical activity (9) have been reported in endurance athletes. However, exercise induced bronchospasm (EIB) occurs more commonly in elite athletes than in the general population (10). Furthermore, the prevalence is even higher among certain groups of athletes (long distance runners, cyclists, skiers and swimmers) than among athletes in general (11).

Although ventilatory limitation has been reported in highly fit athletes as a consequence of high air flow generated during exercise (12), the question of whether BHR in such athletes may induce bronchial obstruction during exercise and subsequently promote airflow limitation remains to be investigated (13). Clinical and functional aspects of post exercise asthma often vary between sportsmen and sedentary persons. 
It has been suggested that high-level training could contribute to the development of BHR (7). Yet, the comparative effects of different sports on airway functions remain to be determined.

Football and judo are two very different sports. However, they are similar in that they include aerobic and anaerobic components. The amount of aerobic and anaerobic activity varies among these sports (14). Indeed, judo is an individual sport which is played indoors on a tatami and its training increases equilibrium, coordination, speed, strength, suppleness, skill, endurance, and resistance (15). Thus, competitive judo can be described as a combative, high intensity sport in which the athlete attempts to throw the opponent onto his back or to control him during groundwork combat (16). On the other hand, football is a team sport that is played in an outdoor field and training is characterized by short-duration high-speed runs, jumps, headings, and ball disputes, besides other activities, such as trots, low-speed running and walks (17).

To the best of our knowledge, there is very limited data available regarding the adaptive response of the lung function parameters to training in judo and football especially in prepubertal children. However, our study expands past research by comparing the BHR between these two different styles of sports and there is no study which has compared the BHR between two sports at pre-pubescent age. Thus, based upon the results of previous studies, we hypothesized that footballers have more BHR than judokas.

\section{Objectives}

The aim of this study was to identify and compare the degree and frequency of EIB of pre-pubertal boys in football, judo and control groups in order to investigate respiratory health consequences.

\section{Patients and Methods}

\subsection{Participants}

Ninety six pre-pubertal boys ( 32 footballers, 32 Judokas and 32 healthy sedentary subjects) were enrolled in the study. The tests were in the in-season phase of competition and all subjects were clinically healthy and had no history of recent infectious disease, asthma or cardiorespiratory disorders. The athletic subjects were selected according to the exclusion criteria defined as follows: Subjects not having a good health at the moment of tests, subjects who are non-confirmed, and who did not have a regular presence in their training sessions or having been engaged for less than 3 years. On the basis of these criteria 24 subjects from 120 were excluded. Finally, 96 athletes were included in subsequent analysis. Control subjects were randomly recruited by draw from primary schools of the same location of the experimen- tal group and they were engaged in $\leq 2$ hours of physical activity per week at school. The football players were recruited from the sports club of Sfax which is one the four most popular and greatest football teams in Tunisia in the first league of professional football and judo players were recruited from two clubs: the sports club of Sfax and the club of sports stadium of Sfax which are known to have the best youth judokas in Tunisia. All football and judo players were enrolled in a training program which consisted of four sessions a week (each session lasting for about 90 minutes) in addition to the weekly games in the official national championship usually held on Sundays. The training of the footballers was outdoors on a synthetic turf for athletic fields and was focused specially on technique, agility, balance, coordination and speed exercises and, in judo, the training was indoors in a well-equipped hall and focused on technique, physical coordination, flexibility, body control, balance and, fast reflexive action. All subjects gave their written consent and the study protocol was approved by the local ethics committee. Physical and physiological measurements were done; body composition was estimated with the skinfold method of Durnin and Wormersley (18). Each skinfold thickness was measured in duplicate on the left side of the body, and the mean value was used for calculation. The errors of measurement were $<1 \mathrm{~mm}$, and the reliability was $>95 \%$. All the anthropometric measurements of all subjects were taken by the same technician resident in the laboratory. The pubertal status was assessed using Tanner stage (19). All the children were tanner stage 1 according to genitalia and pubic hair development by a nurse resident in the laboratory and experienced in the use of the technique.

\subsection{Questionnaires}

A dietary questionnaire was completed by the subjects and their parents. Dietary intake of calories, proteins, lipids and carbohydrate of the subjects was recorded for a week. The treatment results are achieved by a nutrition specialist using the "Epi Info 6" software.

A standardized questionnaire to determine socio-economic level (20) was administered. It consisted of questions to determine the ethnicity and educational status of parents, standard of living, smoking, internal and external pollution, and estimated quantification of their physical activity.

\subsection{Spirometric and Exercise Challenge Test}

Spirometric tests were performed at rest before exercise using a body plethysmograph (Sensor Medics V6200 Auto box; Sensor Medics Co., California, USA). Then, an exercise test was performed in a laboratory in early spring when ambient temperature was approximately $20^{\circ} \mathrm{C}\left(68^{\circ} \mathrm{F}\right)$ and humidity was low (38\%), on a cyclo-ergometer (Sensor Medics: $V_{\max }$ encore 29c; 
Sensor Medics Co., California, USA). Cardiorespiratory variables were determined using a calibrated breath by breath system allowing continuous measurement of heart rate, oxygen uptake and lung ventilation. Each subject performed a continuous and progressive exercise test to exhaustion. During the test, the pedaling rate was kept constant at $60 \mathrm{rpm}$. After a 3 min warmup period at a work rate of 30 watts, 10 watt increments were applied every minute until the pedaling rate could no longer be sustained.

Each subject was instructed and verbally encouraged to give maximal effort during the test. Finally, spirometry was performed at 5,10 and 15 minutes after the end of the exercise. Criteria for EIB were a decrease from baseline in FEV1 of $10 \%$ or greater (21-23).

\subsection{Air Pollution Concentrations}

Air pollution concentrations were measured continuously at the fixed site of the Sfax south station. The pollutants' measurement site was selected so that it was close to the living area of the participating subjects. Data on air quality was obtained from the national agency of environment protection in Tunisia, at the study site. Data on particulate matter (PM10) and nitrogen dioxide $\left(\mathrm{NO}_{2}\right)$ were measured daily and the results were expressed as annual mean concentrations; the agency also measured 24-hour mean concentrations of sulfur dioxide $\left(\mathrm{SO}_{2}\right)$ and 8-hour mean concentrations of ozone $\left(\mathrm{O}_{3}\right)$. All these measurements were used as daily air pollution indicators for children under the same exposure conditions. The time-specific measures were obtained from a permanent background monitor that operated continuously during the study period. There is a very small number of missing values, due mainly to power failure.

\subsection{Statistical Analysis}

Statistica Kernel version 5.5 was used to analyze the data. Descriptive statistics were expressed as mean (SD) for each variable. Analysis of variance (ANOVA) was carried out to detect the effects of type of sport (football or judo). Significance was set at an alpha level of 0.05 .

\section{Results}

Table 1 shows the physical and lung function measurements in the three groups. There was no significant difference in age, standing height, body weight and baseline spirometric values (FVC, TLC, FEV1, and $\mathrm{PEF}$ ) among the 3 groups ( $\mathrm{P}>0.05)$. Footballers and judokas had a similar lean mass and these values were higher than the control group $(\mathrm{P}<0.01)$. Furthermore, there was a significant difference $(P<0.05)$ between the three groups in fat mass; the highest values were in the control group compared to the judokas and footballers.
The judokas had higher fat mass than the footballers. The body mass index (BMI) of the judokas was significantly higher $(\mathrm{P}<0.05)$ than both footballers and the control group who had similar values.

Figure 1 shows the daily calories intake. Figure 2 summarizes the amount of each macronutrient (carbohydrate, lipids and protein). There is no difference in nutritional status between all groups. Figure 3 shows the socio-economic variables, Anova showed no significant difference in the results gathered from parameters such as the occupation of father and mother and the house type.

Table 2 shows the exercise test parameters. There was no significant difference in maximal oxygen consumption $\left(\mathrm{VO}_{2 \text { max }}\right)$ related to body weight between the three groups ( $P>0.05)$. Similarly, no significant differences were found in maximal heart rate $\left(\mathrm{HR}_{\max }\right)$. However, there was a significant difference in $\mathrm{P}_{\text {max }}(\mathrm{P}<0.01)$ between the groups; the values in the footballers and the judokas were similar and were higher than the control group. The maximal minute ventilation of the judokas was significantly higher $(\mathrm{P}<0.01)$ than both footballers and the control group. Furthermore, there was a significant difference in the respiratory exchange ratio ( $P$ $<0.001$ ) among all groups; the values of the footballers were higher than the control group and lower than the judokas.

The time when the greatest percent of decline in FEV1 from baseline occurred in the footballers was as follows: 16 of 32 (50\%) experienced the greatest decline in FEV1 at 5 minutes post-exercise; 14 of 32 (43.75\%) at 10 minutes post-exercise; and 6 of 32 (18.75\%) at 15 minutes post-exercise respectively. In the group of judo, 9 of 32 (28.12\%) had BHR after a decrease of FEV1 at 5 minutes post-exercise; 10 of 32 (32.25\%) at 10 minutes post-exercise; 7 of $32(21.87 \%)$ at 15 minutes post-exercise. In addition, 9 of $32(28.12 \%)$ of the control subjects demonstrated a decrease in FEV1 at 5 minutes post-exercise exactly like the group of judo; 6 of 32 (18.75\%) at 10 minutes post-exercise, and 10 of 32 (31.25\%) at 15 minutes postexercise see the figures.

FEV1 values were measured after the exercise challenge test. In fact, we have found a significant decrease in FEV1 only at 5 minutes post exercise in footballers and judokas $(\mathrm{P}=0.032<0.05)$. The least significant difference (LSD) test in the post-hoc comparisons indicates a significant difference only between the footballers and the judokas. There is no significant difference in FEV1 between all groups at 10 and $15 \mathrm{~min}$ (Table 3 ).

Table 4 shows the air pollutants variable. All the values of PM10, $\mathrm{SO}_{2}$ and $\mathrm{O}_{3}$ are located at the first interim target (IT) level of the world health organization (WHO) air quality guidelines (AQG). This level corresponds to the highest mean concentrations. The level of IT-1 has been shown to be associated with significant mortality in the developed world. The value of NO2 respects that of the WHO air quality guidelines. 
Triki M et al.

Table 1. Physical Anthropometric and Lung Functions Measurements of the Three Groups a,b,c

\begin{tabular}{lcccc}
\hline Variables & Football & Judo & Control & PValues \\
\hline Age, months & $129.88 \pm 9.94$ & $130.56 \pm 9.62$ & $130.91 \pm 9.10$ & 0.908 \\
Weight, Kg & $35.91 \pm 5.46$ & $38.41 \pm 5.98$ & $36.97 \pm 5.65$ & 0.217 \\
Height, m & $1.43 \pm 0.08$ & $1.44 \pm 0.06$ & $1.46 \pm 0.07$ & 0.178 \\
\hline BMI, Kg/m & $17.43 \pm 1.62$ & $18.40 \pm 2.17$ & $17.25 \pm 2.05$ & $0.043^{\mathrm{d}}$ \\
\hline Lean mass, Kg & $11.21 \pm 1.09$ & $11.45 \pm 1.03$ & $10.42 \pm 1.25$ & $0.001^{\mathrm{e}}$ \\
\hline Fat mass, Kg & $10.97 \pm 4.71$ & $13.21 \pm 5.57$ & $15.04 \pm 6.39$ & $0.017^{\mathrm{d}}$ \\
\hline FVC, L & $2.35 \pm 0.37$ & $2.44 \pm 0.38$ & $2.49 \pm 0.33$ & 0.295 \\
TLC, L & $3.50 \pm 0.57$ & $3.72 \pm 0.73$ & $3.66 \pm 0.56$ & 0.736 \\
FEV1, L & $2.11 \pm 0.28$ & $2.17 \pm 0.31$ & $2.20 \pm 0.29$ & 0.427 \\
PEF, $\mathbf{l} / \mathbf{s}$ & $4.27 \pm 0.61$ & $4.37 \pm 0.73$ & $4.54 \pm 0.78$ & 0.298 \\
\hline
\end{tabular}

a Values are presented as Mean \pm SD

b $\mathrm{No}=32$.

c Abbreviations: BMI: body mass index ; FVC: forced vital capacity ; TLC: total lung capacity; FEV1: forced expiratory volume in 1 second; PEF: peak expiratory flow.

$\mathrm{d} \mathrm{P}<0.05$.

e $\mathrm{P}<0.01$.

\begin{tabular}{|c|c|c|c|c|}
\hline Variables & Football & Judo & Control & PValues \\
\hline Power max, W & $114.06 \pm 22.34$ & $115.22 \pm 24.23$ & $98.59 \pm 17.67$ & $0.003^{\mathrm{d}}$ \\
\hline $\mathrm{VO}_{2 \max }, 1 / \mathrm{min} / \mathrm{Kg}$ & $53.86 \pm 7.28$ & $52.45 \pm 7.86$ & $53.25 \pm 7.48$ & 0.757 \\
\hline RER $_{\text {max }}$ & $1.07 \pm 0.12$ & $1.12 \pm 0.16$ & $0.99 \pm 0.09$ & $0.0002^{\mathrm{e}}$ \\
\hline $\mathrm{VE}_{\max }, 1 / \mathrm{mn}$ & $62.86 \pm 14.38$ & $74.61 \pm 19.99$ & $62.92 \pm 11.33$ & $0.003^{d}$ \\
\hline$H_{\text {max }}$, bpm & $186.55 \pm 8.57$ & $188.19 \pm 11.70$ & $187.56 \pm 10.42$ & 0.217 \\
\hline
\end{tabular}

a Values are presented as Mean \pm SD.

b $\mathrm{No}=32$.

C Abbreviations: $\mathrm{VO}_{2}$ max: oxygen consumption; $\mathrm{RER}_{\text {max }}$ : maximal respiratory exchange ratio: maximal minute ventilation; HR max maximal heart rate.

d $\mathrm{P}<0.01$.

e $\mathrm{P}<0.001$.

Table 3. Percentage of Fall of FEV1 After Exercise ${ }^{a, b}$

\begin{tabular}{|c|c|c|c|c|}
\hline & Football & Judo & Control & P Values \\
\hline$\%$ of fall of FEV $_{1}$ After 5 & $(-) 9.60(6.18)$ & $(-) 5.41(5.85)$ & $(-) 8.50(7.56)$ & $0.036^{c}$ \\
\hline$\%$ of fall of FEV ${ }_{1}$ After 10 & $(-) 7.70(4.96)$ & $(-) 7.71(7.64)$ & $(-) 7.00(7.49)$ & 0.89 \\
\hline$\%$ of fall of FEV ${ }_{1}$ After 15' & $(-) 6.00(5.70)$ & $(-) 5.28(7.47)$ & $(-) 6.81(7.18)$ & 0.67 \\
\hline
\end{tabular}

a $\mathrm{No}=32$

b FEV1, forced expiratory volume in $1 \mathrm{~s}$.

c $\mathrm{P}<0.05$.

Table 4. Distribution of Air Pollutants Variables ${ }^{a}$

\begin{tabular}{lccc}
\hline Air Polluant & Values, $\boldsymbol{\mu g} / \mathbf{m}^{3}$ & WHO Guidelines, $\boldsymbol{\mu g} / \mathbf{m}^{3}$ & WHO Interim Target Levels \\
\hline $\mathbf{P M}_{\mathbf{1 0}}$, annual mean & 89 & 20 & 1 \\
$\mathbf{N O}_{2}$, annual mean & 25 & 40 & AQG \\
$\mathbf{S O}_{\mathbf{2}}$, 24-hours mean & 216 & 20 & 1 \\
$\mathbf{O}_{\mathbf{3}}, \mathbf{8}$-hours mean & 114 & 100 & 1 \\
\hline $\begin{array}{l}\text { a Abbreviations: PM10, particulate matter; NO2, nitrogen dioxide; SO2, sulfur dioxide; O3, ozone; AQG, air quality guidelines; WHO: world health } \\
\text { organization }\end{array}$
\end{tabular}


Triki M et al.

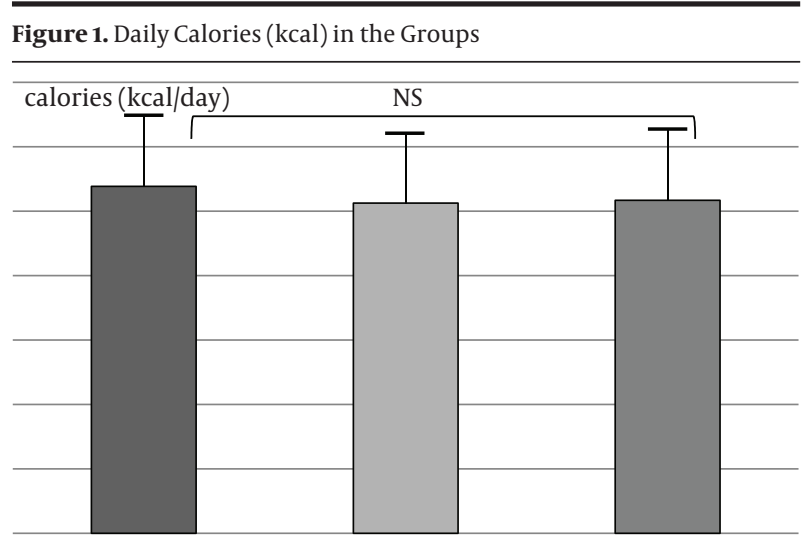

NS: Non-significant.

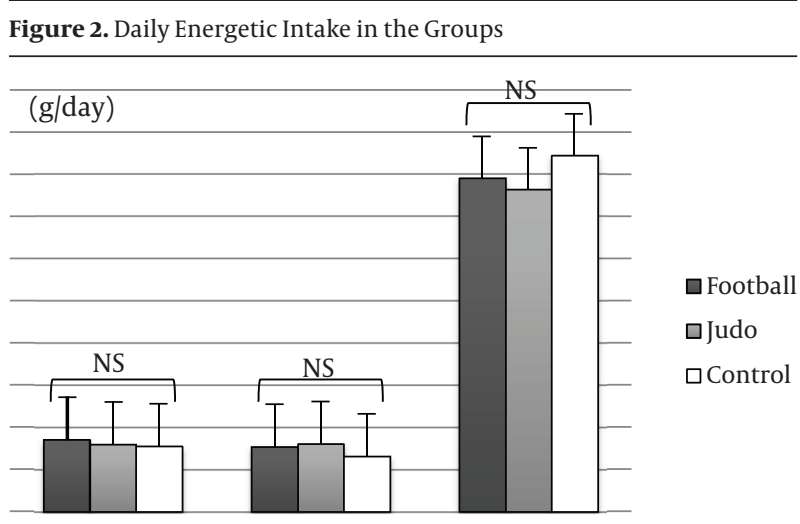

NS: Non-significant.

Figure 3. Level of the Father and Mother Occupation and the Kind of the House in the Groups

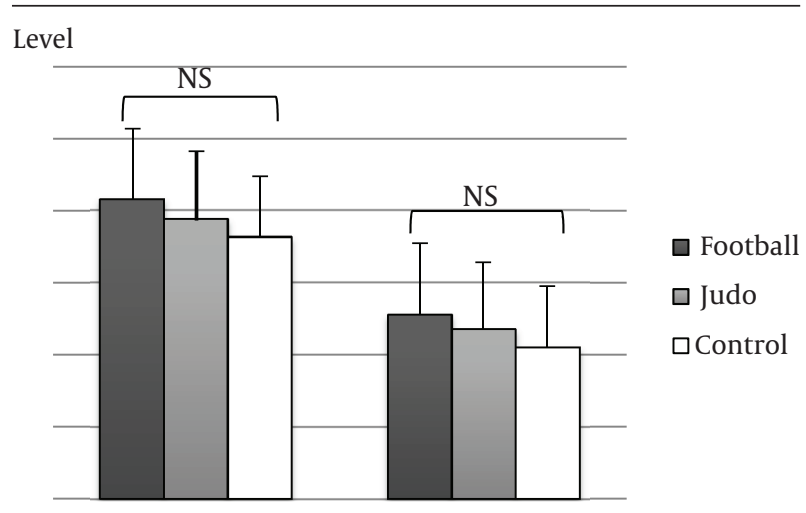

NS: Non-significant

\section{Discussion}

This study shows that in pre-pubertal boys, the footballers had significantly higher prevalence of BHR than judokas reflected by the percentage of fall of FEV1. The Footballers have more BHR than both judokas and con- trol subjects, especially at 5 minutes after the exercise.

Post exercise spirometry tests revealed the presence of EIB (a decrease from baseline FEV1 of at least 10\%) in 16 of $32(50 \%)$ footballers. This was the greatest decline of FEV1 among the groups at all times $(5,10$, and 15 minutes after the exercise challenge test). There was a significantly higher decrease in mean FEV1 at 5 minutes in pre-pubertal football boys than in judokas with BHR.

Various studies in North Africa have been conducted to determine the prevalence of asthma but there were marked differences among these studies probably because of methodological considerations. The prevalence ranged from 2.4 to $3.4 \%$ in studies before 1990 and from 6 to $12 \%$ in the later ones (24). In a study using the "International Study of Asthma and Allergies in Childhood" (ISAAC) methodology conducted in the Tunis region on children aged 13-14 years, the prevalence was found to be $5.4 \%$ (24). Only one recent study has been performed in Tunisian elite athletes showing the prevalence of EIB as $13 \%$ (25). The prevalence of asthma has ranged from $4 \%$ to $59 \%$ in various athletes studies. This wide variation is mainly due to different types of training and training environments. Also differences in the definition and diagnosis of asthma may have some impact on the mentioned range. In fact, a high prevalence of asthma has been found among those athletes competing in endurance events such as cycling, swimming, cross-country skiing, and long-distance running (26-30).

Environmental factors as well as the type and content of the inhaled air, could play an important role. Even if most sports are practiced in various air conditions all year long, many sports are predominantly practiced either in cold, dry or humid air (31). For athletes who train outdoors, the quality of the inhaled air varies and the presence of different pollutants may contribute to the development of EIB (31). In addition, evaporative and convective loss of heat from airway could be increased with ventilation as well as the respiration water loss which decreases during exercise while breathing dry warm air may develop bronchoconstriction (32). For the athletes who practice their sport in indoor areas, the exposure to such contaminants and to a variety of organic pollutants could contribute to certain respiratory problems (33).

For our football players, the results showing the Percentage of subjects having a decline of FEV1 more than $10 \%$ confirm those found by Weiler et al. (34) (50\%) and Ross (35) (56\%) after inhalation of a pharmacological agent. The difference between judokas and football players could be explained by the type of exposure of these athletes during their practice/training. The judokas trained in a hall and, therefore, they are relatively less exposed to air pollution and aeroallergens than football players. Exposure to air pollution was associated with reduced respiratory function and may lead to a decline in physical efficiency in pre-adolescent children $(35,36)$. Also, the pollutionrelated to reduction of lung function in childhood might be related, at least partially, to long-term exposure to par- 
ticulate air pollutants, and especially in those children who spend more time practicing outdoor sports (36), and there is considerable evidence that asthmatic persons are at increased risk of developing exacerbations with exposure to $\mathrm{O}_{3}, \mathrm{NO}_{2}, \mathrm{SO}_{2}$ and inhalable PM pollution (37). The risk of inhalation of pollutants in the lungs could be significantly increased in our football players, who trained outdoor causing more bronchoconstriction because of the concentrations of ozone $\left(\mathrm{O}_{3}\right)$, sulfur dioxide $\left(\mathrm{SO}_{2}\right)$, and particulate matter (PM10) who exceeded the levels allowed by the WHO air quality guidelines especially the values of $\mathrm{SO}_{2}$ and PM10. These results may explain at least partly how our footballers have more prevalence of bronchoconstriction than the general population and judokas who are constantly protected indoor, especially as we have registered no significant difference in dietary intake and socioeconomic status among the three groups in our study.

Football and judo training are totally different. In football, the activity in this sport is based on the race (17) on an area whose size is much larger than a tatami of judo. In this regard, it has been indicated that running is the most effective way to provoke EIB (28). That is why the EIB in football is more marked than in judo. Furthermore, athletes who train hard, particularly long distance runners, are frequently exposed to factors such as cold air (38) and aeroallergens (39) which are known to exacerbate bronchoconstriction.

This study has shown that the prevalence of BHR in judokas is relatively similar to the control group, especially at 5 minutes after the end of the exercise. This result confirms those of Michalak et al. (40) who find that among the various sporting disciplines studied, the lowest prevalence of asthma is in judo (identical to that of the general population). In fact, judo is a succession of short and intense exercises with a very short recovery time. Furthermore, among the mechanisms invoked to explain the prevalence of asthma in the sport, hyperventilation appears to play a decisive role. Michalak et al.(40) indicated that hyperventilation increases the contact between the bronchial mucosa and allergens and therefore increasing BHR.

Our sedentary group has an EIB less than sporting subjects; this may be due to the fact that they are seldom exposed to the volumes and/or intensities of activities leading to hyperventilation. Unlike the sedentary subjects that rarely prolong exercises inducing hyperventilation beyond $5 \mathrm{~min}$, the athlete even from a sport dominated by anaerobic extends his actions or only partially recovers between two periods (i.e. Judo). It is, therefore, logical that the occurrence of dyspnea appears during exercise and not at recovery.

It has been indicated that atopy is a major risk factor for EIB (28). In a recent study, Sallaoui et al. (41) indicated that, in a total of 326 athletes who underwent skin tests, atopy was identified in $26.9 \%$ (88/326). This prevalence of atopy among Tunisian athletes was not much different from the general population (41). Some authors indicated that atopy in athletes may be partly related to exercising in extreme or particular environmental conditions which may favor its expression in the predisposed subjects $(42,43)$.

Furthermore, the American thoracic society (ATS) guidelines (44) and studies by others (45-49) recommended that laboratory-based EIB testing should include an exercise challenge of 6 to 8 minutes in ambient conditions $\left(20-25^{\circ} \mathrm{C}\right.$; relative humidity $\left.(\mathrm{RH})<50 \%\right)$ at $80 \%$ to $90 \%$ of predicted $\mathrm{HR}_{\text {max }}$ with pre-spirometry and post-spirometry, the elite athlete population may require a greater exercise intensity under dry air conditions (50). However, the environmental conditions in the laboratory included a relative humidity of $60 \%$ which in itself may protect against EIB (51).

Otherwise, BHR occurred during recovery time and therefore alter the performance of the following exercises. However, the degree of EIB of pre-pubertal boys in Football is higher than that in Judo and control groups, especially after 5 minutes of the exercise challenge test, after that the degree of EIB decreases at 10 and 15 minutes. Thus, in football match, the recovery between the two half times ( $\sim 15$ minutes) can reduce bronchoconstriction as FEV1 returns to baseline values, so the second time begin without alteration of airway flows. However, it is not the same event for judo, because the recovery times are very short to allow to FEV1 to reach the baseline values.

\subsection{Limitations of the Study}

This study suffers from some limitations that need to be acknowledged and addressed such as the relatively small sample size. An additional limitation of our study is that the mean of $\mathrm{HR}_{\max }$ of all groups does not reach the predicted $\mathrm{HR}_{\text {max }}$. This finding indicates that our subjects did not achieve a true maximum effort because they feel leg fatigue before reaching exhaustion and therefore limiting maximum cardiorespiratory responses. Moreover, the environmental conditions in the laboratory included a relative humidity of $60 \%$ which in itself may protect against EIB (51). This factor may be a limitation for this study; it must be regarded with some caution. In fact, for athletes it has been maintained that performing field tests with the specific exercise type employed in their type of sport is optimal for describing the epidemiology and diagnosing the pathogenesis of the respiratory and allergic disorders in sports EIB and asthma. More studies are needed to confirm the results in appropriate conditions. However, in our study, the aerobic test protocol on ergo cycle needs to extend the time to exhaustion to reach the predicted $\mathrm{HR}_{\text {max }}$ and the $\mathrm{VO}_{\text {max }}$; it means that the time spent on the work load must be reviewed.

\subsection{Practical Applications}

It appears that the decrease of FEV1 after exercise in prepubertal boys playing football was larger than those in 
those playing judo. However, the decreases of FEV1 after playing both football and judo did not change compared with those in control group.

We considered that the changes of $\mathrm{P}_{\text {max }}, \mathrm{VO}_{\text {max }}, \mathrm{PEF}$, and $\mathrm{HR}_{\text {max }}$ between football play and judo play did not have a significant differences. These results indicated that this exercise test did not satisfy enough quantity of motion.

Although, the occurrence of BHR was greater in footballers than the Judo and Control groups, aerobic performance as measured by $\mathrm{VO}_{\max }$ was not significantly different between groups. This poses the question: does BHR influence performance?

The present study suggests an association between the occurrence of BHR and the competitive event undertaken by footballers and judokas in prepubertal boys. The footballers had significantly higher prevalence of BHR than judokas. This could be explained by differences in the rate of ventilation found among athletes competing in endurance events, as well as to atopy, related to exercising in extreme or particular environmental conditions which may favor its expression and exposure to inhalant allergens and pollutants during these events. More studies are needed to clarify this association.

\section{Acknowledgements}

This research was supported by a grant from the Functional respiratory exploration service, Habib Bourguiba hospital of Sfax, Tunisia. The authors would like to thank the pneumologist Mohsen Maalej for his assistance and the national agency of environment protection, Tunisia for offering us the pollutants' values. They are grateful to all subjects who took part to this study.

\section{References}

1. Shaaban R, Leynaert B, Soussan D, Anto JM, Chinn S, de Marco $\mathrm{R}$, et al. Physical activity and bronchial hyperresponsiveness: European Community Respiratory Health Survey II. Thorax. 2007;62(5):403-10.

2. Rasmussen F, Lambrechtsen J, Siersted HC, Hansen HS, Hansen NC. Low physical fitness in childhood is associated with the development of asthma in young adulthood: the Odense schoolchild study. Eur Respir J. 2000;16(5):866-70.

3. Huovinen E, Kaprio J, Laitinen LA, Koskenvuo M. Social predictors of adult asthma: a co-twin case-control study. Thorax. 2001;56(3):234-6.

4. Gelb AF, Tashkin DP, Epstein JD, Gong HJ, Zamel N. Exercise-induced bronchodilation in asthma. Chest. 1985;87(2):196-201.

5. Rundell KW, Spiering BA, Judelson DA, Wilson MH. Bronchoconstriction during cross-country skiing: is there really a refractory period? Med Sci Sports Exerc. 2003;35(1):18-26.

6. Denguezli-Bouzgarrou M, Sriha B, Ben Cheikh I, Ben Turkia W, Tabka Z, Zbidi A. Effect of endurance exercise on airway cells in runners. Sci Sport. 2006;21(2):99-100.

7. Langdeau JB, Turcotte H, Bowie DM, Jobin J, Desgagne P, Boulet LP Airway hyperresponsiveness in elite athletes. Am J Respir Crit Care Med. 2000;161(5):1479-84.

8. Nystad W, Harris J, Borgen JS. Asthma and wheezing among Norwegian elite athletes. Med Sci Sports Exerc. 2000;32(2):266-70.

9. Wilber RL, Rundell KW, Szmedra L, Jenkinson DM, Im J, Drake SD Incidence of exercise-induced bronchospasm in Olympic winter sport athletes. Med Sci Sports Exerc. 2000;32(4):732-7.
10. Parsons JP, Kaeding C, Phillips G, Jarjoura D, Wadley G, Mastronarde JG. Prevalence of exercise-induced bronchospasm in a cohort of varsity college athletes. Med Sci Sports Exerc. 2007;39(9):1487-92.

11. Belda J, Ricart S, Casan P, Giner J, Bellido-Casado J, Torrejon M, et al. Airway inflammation in the elite athlete and type of sport. $\mathrm{Br} J$ Sports Med. 2008;42(4):244-8.

12. Johnson BD, Saupe KW, Dempsey JA. Mechanical constraints on exercise hyperpnea in endurance athletes. J Appl Physiol (1985). 1992;73(3):874-86.

13. Verges S, Devouassoux G, Flore P, Rossini E, Fior-Gozlan M, Levy $\mathrm{P}$, et al. Bronchial hyperresponsiveness, airway inflammation, and airflow limitation in endurance athletes. Chest. 2005;127(6):1935-41.

14. Andreoli A, Melchiorri G, Brozzi M, Di Marco A, Volpe SL, Garofano $P$, et al. Effect of different sports on body cell mass in highly trained athletes. Acta Diabetol. 2003;40 Suppl 1:S122-5.

15. Charreire J, Karsenty G, Bouchard P, Schaison G. Effect of carbimazole treatment on specific and non-specific immunological parameters in patients with Graves' disease. Clin Exp Immunol. 1984;57(3):633-8.

16. Katralli J, Goudar SS. Anthropometric Profile and Special Judo Fitness levels of Indian Judo Players. Asian J Sports Med. 2012;3(2):113-8.

17. Coelho DB, Coelho LG, Mortimer LA. Energy expenditure estimation during official soccer matches. Braz J Biomotric. 2010;4:246-55.

18. Durnin JVGA, Womersley J. Body fat assessed from total body density and its estimation from skinfold thickness: measurements on 481 men and women aged from 16 to 72 Years. British J Nut. 2007;32(01):77-97.

19. Tanner JM. Physique and body composition. Larson L editor. New York: Macmillan; 1974.

20. Ferris BG. Epidemiology Standardization Project. II. Recommended respiratory disease questionnaires for use with adults and children in epidemiological research. Am Rev Respir Dis. 1978;118::7-57.

21. Anderson DA. Exercise-induced asthma. . 4 ed. Middleton E, Reed CE, Ellis EF editors. Mosby: St Louis; 1993.

22. Sidiropoulou MP, Fotiadou EG, Tsimaras VK, Zakas AP, Angelopoulou NA. The effect of interval training in children with exercise-induced asthma competing in soccer.J Strength Cond Res. 2007;21(2):446-50.

23. Voy RO. The U.S. Olympic Committee experience with exercise-induced bronchospasm, 1984. Med Sci Sports Exerc. 1986;18(3):328-30.

24. Khaldi F, Fakhfakh R, Mattoussi N, Ben Ali B, Zouari S, Khemiri M. Prevalence and severity of asthma, allergic rhinoconjunctivitis and atopic eczema in "Grand Tunis" schoolchildren: ISAAC. Tunis Med. 2005;83(5):269-73.

25. Sallaoui R, Chamari K, Chtara M, Alaranta A, Manai Y, Ghedira $\mathrm{H}$, et al. Asthma in Tunisian elite athletes. Int J Sports Med. 2007;28(7):571-5.

26. Alaranta A, Alaranta H, Palmu P, Alha P, Pietila K, Heliovaara $\mathrm{M}$, et al. Asthma medication in Finnish olympic athletes: no signs of inhaled beta2-agonist overuse. Med Sci Sports Exerc. 2004;36(6):919-24.

27. Helenius IJ, Tikkanen HO, Haahtela T. Association between type of training and risk of asthma in elite athletes. Thorax. 1997;52(2):157-60.

28. Helenius IJ, Tikkanen HO, Sarna S, Haahtela T. Asthma and increased bronchial responsiveness in elite athletes: Atopy and

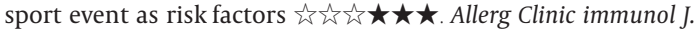
1998;101(5):646-52.

29. Koh YI, Choi IS. Seasonal Difference in the Occurrence of ExerciseInduced Bronchospasm in Asthmatics: Dependence on Humidity. Respiration. 2002;69(1):38-45.

30. Maiolo C, Fuso L, Todaro A. Prevalence of asthma and atopy in Italian Olympic athletes. . Int J Sports Med. 2003;25::139-44.

31. Langdeau JB, Boulet LP. Prevalence and Mechanisms of Development of Asthma and Airway Hyperresponsiveness in Athletes. Sports Med. 2001;31(8):601-16.

32. Tabka Z, Ben Jebria A, Vergeret J, Guenard H. Effect of dry warm air on respiratory water loss in children with exercise-induced asthma. Chest. 1988;94(1):81-6. 
33. Helenius I, Rytila P, Sarna S, Lumme A, Helenius M, Remes V, et al. Effect of continuing or finishing high-level sports on airway inflammation, bronchial hyperresponsiveness, and asthma: a 5-year prospective follow-up study of 42 highly trained swimmers. J Allergy Clin Immunol. 2002;109(6):962-8.

34. Weiler JM, Metzger WJ, Donnelly AL, Crowley ET, Sharath MD. Prevalence of bronchial hyperresponsiveness in highly trained athletes. Chest. 1986;90(1):23-8.

35. Ross RG. The prevalence of reversible airway obstruction in professional football players. Med Sci Sports Exerc. 2000;32(12):1985-9.

36. Rouatbi S, Latiri I, Zaouali M, Tabka Z, Dessanges JF, Mrizek N, et al. [Air pollution and bronchial hyperresponsiveness]. Tunis Med. 1999;77(1):27-32.

37. Zebrowska A, Mankowski R. Effects of long-term exposure to air pollution on respiratory function and physical efficiency of preadolescent children. Eur J Med Res. 2010;15 Suppl 2:224-8.

38. D'Amato G, Liccardi G, D'Amato M, Cazzola M. Outdoor air pollution, climatic changes and allergic bronchial asthma. Eur Respir J. 2002;20(3):763-76.

39. Strauss RH, McFadden EJ, Ingram RJ, Jaeger JJ. Enhancement of exercise-induced asthma by cold air. NEngl JMed.1977;297(14):743-7.

40. Michalak T, Flore P, Bouvat E, Vergès S, Samuel MJ, Favre-Juvin A. Prévalence de l'asthme chez l'athlète, influence de la discipline sportive et des conditions environnementales. Sci Sport. 2002;17(6):278-85.

41. Sallaoui R, Chamari K, Mossa A, Tabka Z, Chtara M, Feki Y, et al. Exercise-induced bronchoconstriction and atopy in Tunisian athletes. BMC Pulm Med. 2009;9:8.

42. Benzarti M, Mezghani S, Jarray M, Garrouche A, Khirouni S, Klabi $\mathrm{N}$. [Skin test reactivity to seven aeroallergens in a Sousse area population sample].Tunis Med. 2002;80(8):450-4.
43. Didier A, Mazieres J, Kouevijin G, Tetu L, Riviere D. [Sport and atopy]. Rev Mal Respir. 2003;20(5 Pt 1):727-34.

44. Crapo RO, Casaburi R, Coates AL, Enright PL, Hankinson JL, Irvin CG, et al. Guidelines for methacholine and exercise challenge testing-1999. This official statement of the American Thoracic Society was adopted by the ATS Board of Directors, July 1999. Am J Respir Crit Care Med. 2000;161(1):309-29.

45. Helenius I, Haahtela T. Allergy and asthma in elite summer sport athletes. JAllergy Clin Immunol. 2000;106(3):444-52.

46. Anderson SD, Silverman M, Tai E, Godfrey S. Specificity of exercise in exercise-induced asthma. Br Med J. 1971;4(5790):814-5.

47. Eggleston P, Rosenthal R, Anderson S, Anderton R, Bierman C, Bleecker E, et al. Guidelines for the methodology of exercise challenge testing of asthmatics. J Allergy Clin Immunol. 1979;64(6):642-5.

48. Godfrey S, Silverman M, Anderson SD. The use of the treadmill for assessing exercise-induced asthma and the effect of varying the severity and duration of exercise. Pediatrics. 1975;56(5 pt-2 suppl):893-8.

49. Mahler DA. Exercise-induced asthma. Med Sci Sports Exerc. 1993;25(5):554-61.

50. Rundell KW, Slee JB. Exercise and other indirect challenges to demonstrate asthma or exercise-induced bronchoconstriction in athletes. J Allergy Clin Immunol. 2008;122(2):238-46.

51. Carlsen KH, Anderson SD, Bjermer L, Bonini S, Brusasco V, Canonica W. Treatment of exercise-induced asthma, respiratory and allergic disorders in sports and the relationship to doping: Part II of the report from the Joint Task Force of European Respiratory Society (ERS) and European Academy of Allergy and Clinical Immunology (EAACI) in cooperation with GA2LEN. Allergy. 2008;63(5):492-505. 